\title{
Rethinking Scholarly Commentary in the Age of Google
}

\author{
Some Preliminary Meditations on Digital Editions
}

\author{
Sarab Neville
}

\begin{abstract}
Recently theorists have suggested that the lens of the social text demystifies an editor's role, positing that texts may be most profitably constructed as a collective conversation between all of the various agents involved in their production and reception. This paper considers these theories in light of studies of group cognition to suggest that modern readers' new relationship to digital information upsets an editor's traditional position as an authority while simultaneously offering a valuable opportunity for reframing discussions about the reliability and accessibility of scholarly evidence.
\end{abstract}

I have bought

Golden opinions from all sorts of people,

Which would be worn now in their newest gloss,

Not cast aside so soon.

— Macbeth (1.7.32-5)

Harold Bloom: I was thinking all day, what questions will you ask? You're recording?

Joshua Cohen: I am. I'm recording on my phone - and we might as well begin with that, because one of the things I wanted to speak with you about was memory. Everyone calls this "a phone," but my generation in particular considers it as something more like an external brain. It stores our sounds, our images, our books. I need this extra storage space, this extra memory, to compensate for my own. But, famously, you don't. You remember everything.

— From a 2018 interview 
$\mathrm{T}_{\mathrm{H}}$ he modern English verb to edit derives from the Latin edare, 'TO PUT FORTH' or 'to give out'. The first accounts of the word in the Oxford English Dictionary suggest that the English term began with definitions that made the verb's indirect object clear: as well as 'to publish', to edit originally meant to 'give to the world' (OED, edit, v., 1). The work of the editor is thus to make available something that was hitherto unavailable, to provide access where once there was none. Because to publish derives from the Latin publicare, 'to make public', the OED's definition further inscribes the editor as someone who serves as a gateway between a text or an artifact and a wider community. Nineteenth- and twentieth-century editors have taken this role as a raison d'être: for example, from its founding in 1864, the Early English Text Society relied on its individual editors' access to the rare book libraries of Oxford and Cambridge in order to produce its myriad volumes of Medieval and Renaissance texts. ${ }^{1}$ Similarly, W.W. Greg's theory of copy text and Fredson Bowers's extensive systems of collation notation and bibliographic description were designed to enable users of scholarly editions to reconstruct the accidental and substantive features of the physical documents that lay behind editions. ${ }^{2}$ As researchers and scholars with access to the remote archives and libraries that contain rare documentary materials, editors are thus able to put forth new forms of texts that make it easier to study unique or rare documents like British Library Cotton MS Vitellius A XV (the manuscript containing Beowulf) or the first quarto text of Hamlet. Gary Taylor, general editor of the Oxford Middleton and the New Oxford Shakespeare, makes this privileged, disseminating position of the editor quite plain: "How can you love a work, if you don't know it? How can you know it, if you can't get near it? How can you get near it, without editors?" (1993, 133).

1. For a history of the EETS, I am indebted to Cowan 2012.

2. Like all other forms of human pursuit, editorial activities work within the technological affordances of their particular historical moments. For example, the theory of "accidentals" laid out in Greg's "Rationale" of 1949 and further developed by Bowers meant that any copy text can be reconstructed by working backwards from a scholarly edition — creating a practical bibliographic resource in an age before scholars were easily able to fly across oceans to check variant copies. To put it another way, the technologies of twentieth-century travel influenced the technologies of twentieth-century texts. On the rise of leisure air travel, see Lyтн 1993. 
This essay offers some preliminary reflections on editorial authority in scholarly editions of English Renaissance works in light of recent developments in both digital media and studies of cognition. The first section assesses claims that scholarly editions have become more democratic in light of their ability to provide readers with access to facsimiles of the printed and manuscript copy texts that lie behind edited documents. Finding instead that the presence of facsimiles actually reinforces editorial authority, I argue that digital editors can take a different approach to user engagement. By turning their attention towards the production of a networked commentary, digital scholarly editions can use the affordances of digital media to demonstrate explicitly how editors' credibility with readers has always been contingent and intertextual. Such a process will inform an edition's readers not only of the scholarly provenance of a given author or text, but also of editorial and citational practices more broadly. In other words, the technologies of new media offer an opportunity to showcase the ways in which scholars have always made and defended their knowledge claims. To bolster this account, the second section of this paper explores models of group cognition known as "Transactive Memory Systems" and considers the impact of these systems upon established notions of editors' privileged position as those "subjects presumed to know".

\section{I}

While editors have always sought to use their access to unique or restricted documents to bring isolated works to wider scholarly attention, the advent of digital technologies has altered the editorial landscape. Chief among the changes is the apparent shift in the status of editorial authority that results from the ease with which digital scholarly editions are able to present facsimile images of archival materials in order to bolster, rationalize, or legitimize their editors' activities in constructing an edited text. The limited form of analog archival access that Martha Nell Smith $(2002,837)$ calls "By Experts-Only" has, in the age of digital scholarly editions and thematic research collections, made way for a more capacious and egalitarian sort of access that enables other would-be scholars to engage with copies of these materials. ${ }^{3}$ On the surface, the reproduction of archival material

3. "Thematic Research Collections" is a term coined by John Unsworth in a paper delivered at the annual meeting of the Modern Language Association of America in 2000 to describe resources that serve as "digital surrogates for physical 
seemingly eliminates the need for the function of an editor as an intermediary: while in a pre-digital world, the edited copy of an archival document may be recognized as mediated by virtue of its new form, a photo-facsimile of a document is able to offer readers a seemingly unmediated experience. In the case of an edited scholarly edition, ready access to a photo-facsimile of the document that the editor used as copy text offers readers the capacity of checking up on an editor's activities by looking behind an edition's emendations; for example, David Bevington's edition of As You Like It for the Internet Shakespeare Editions is accompanied (as are all ISE texts) by facsimiles of the play in two copies of the First Folio, as well as by facsimiles of the play as it appears in the second (F2), third (F3), and fourth (F4) folios (ISE texts that also have authoritative quarto editions likewise feature facsimiles of quartos). ${ }^{4}$ As a result, in his modernized ISE edition, when Charles explains Rosalind's failure to follow her banished father from the court, Bevington adds a textual note illustrating his adoption of the F3 correction to Charles' speech:
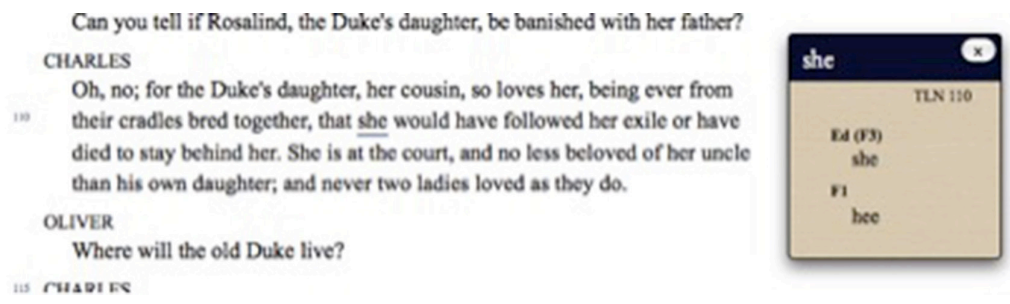

Figure 1. David Bevington's online edition of As You Like It for the Internet Shakespeare Editions. Screenshot by the author.

Because of the ISE's mandate to offer access to Shakespeare's texts in multiple versions, a reader interested in investigating Bevington's insertion of the F3 correction can easily inspect the speech as it appears in either the New South Wales or Brandeis University (shown) copies of F1:

artifacts" or "born-digital evidence for a secondary resource"; for an exploration of the genre, see PAlmer 2004.

4. The Internet Shakespeare Editions can be accessed at http://internetshakespeare.uvic.ca/. 


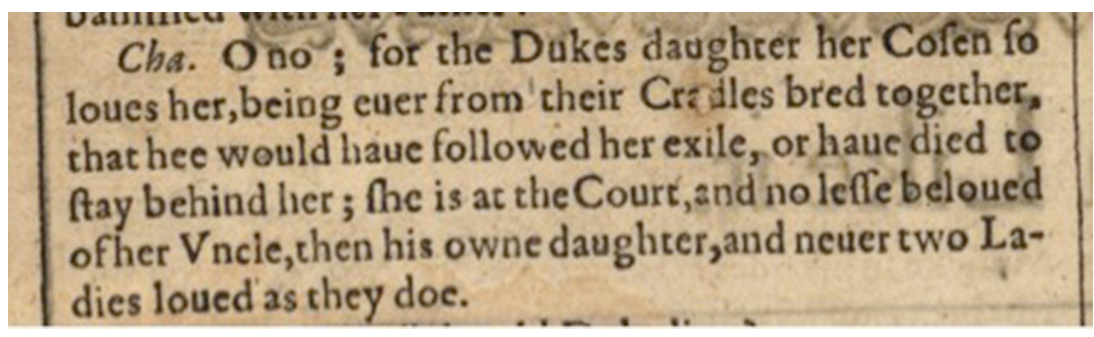

Figure 2. Detail of $\mathrm{Q}^{\mathrm{v}}$ from the Brandeis University copy of Shakespeare's First Folio, as rendered by the Internet Shakespeare Editions. Screenshot by the author.

The ISE's facsimile collection means that Bevington's reader can immediately see the error in William Jaggard and Issac Blount's 1623 text of F1 that her editor has corrected; it also allows her to see the first time that the error was caught and corrected in print in the text of Philip Chetwind's third folio of 1664. Similarly, A Social Edition of the Devonshire MS (BL Add. MS 17492), a scholarly and largely diplomatic edition of a Henrician verse miscellany written in multiple hands, features both facsimile images of the manuscript itself as well as "hand sample tables that open our paleographic attribution process to public scrutiny" (СRомpton et al. 2014, 146)..$^{5}$ I will return to A Social Edition further below.

It bears mentioning that despite superficial appearances to the contrary, what A Social Edition of the Devonshire MS and the ISE offer is not unmediated access to specific copies of their copy texts but access to digital images of them (which are themselves mediated and translated). In some cases, the facsimiles are digitizations of microfiche films of specific copies, putting them at quite a far remove from the original artifacts: some copies are smudged, cropped, and/or rendered only in a high-contrast black and white that eliminates crucial details of the page. But the purpose of the present essay is not to dwell on the mutations that can occur as works are translated between media, as excellent accounts of this phenomenon can be found elsewhere. ${ }^{6}$ Instead, what I am interested in interrogating is the

5. A Social Edition of the Devonshire Manuscript is published in multiple forms including a digital edition on Iter: Gateway to the Middle Ages and Renaissance (http://dms.itercommunity.org/), a print edition published in 2015 through the New Technologies in Medieval and Renaissance Texts series, and the publicly-editable form in Wikibooks: https://en.wikibooks.org/wiki/The_Devonshire_Manuscript.

6. Among the best of these is TAnselle 1989. 
effect of the expansion of documentary access on an editor's traditional forms of textual and scholarly authority as such authority is refigured in the new medium of the digital scholarly edition. Whereas in printed scholarly editions an editor's authority to speak of the text as an expert may have depended on his or her position as a gatekeeper with access to restricted documentary material, the easy distribution of facsimile images in digital editions means that electronic editions have exposed the mechanics of an editor's textual work while simultaneously undercutting an editor's restricted access as the primary means of establishing his or her authority over documentary evidence. Such a new state of affairs has the effect of making an editor's work seem fulfilled by reproducing primary documents in a more accessible and more easily distributed form; a once-restricted textual artifact is now widely available on the web either freely or with a paid subscription, and users may simply evaluate what has been presented.?

Though the documents that contain a Renaissance text exist in an archive regardless of an editor's ministrations (and though the form of those documents may ultimately be traced back to the originating principle of the author), the reader's experience of an author's work in a scholarly edition is necessarily mediated first by the editor's decision to edit and secondly by the editor's translation of the documents into a new textual form. The addition of reproductions of the documents the editor used to construct her edition does not fundamentally change this hierarchy, as the editor's access to the restricted document is still required in order to bring the edition into being. Even in a scholarly edition of a multi-authored, "social" text like the Devonshire MS (which in its Wikibook form may be altered or affected by the activities of the "community of users participating in collective and collaborative knowledge building using social technologies"), the digital edition is still literally effected not by users, but by its editors' originating hands. ${ }^{8}$ As the authors of a recent white paper of the Modern Language Association's Committee on Scholarly Editions suggest, an edition functions as a "mediation [. . .] a medium through which we encounter some

7. More than fifty years ago John Russell Brown anticipated the makeup of current digital scholarly editions, advocating that the needs of most readers would be served best by "a photograph and a fully responsible, modernized, critical text" $(1960,67)$.

8. Ray Siemens et al. 2012, 453. For a discussion of the crucial distinction between 'affect' and 'effect' and its relationship to social theories of textuality, see NEVILLE 2014, 98 n11. 
text or document and through which we can study it". 9 The white paper observes that editions therefore have a responsibility to be upfront with readers about the ways that they have chosen to represent their mediated text so that they can be subject to informed criticism. Because scholarly editions make their "representational apparatus" visible to their readers, readers are able to consider the textual object separately from the interpretive lens through which it has been seen.

But while the new digital medium has not fundamentally changed the nature of the relationship between editors and readers, an editor's authority over the text appears to have shifted. Because the inclusion of copies of the copy text(s) used in the construction of a digital edition can assist a reader in verifying an editor's accuracy in collation and textual representation, the presence of facsimile images in a digital scholarly edition enables readers the ability to scrutinize - and to criticize - editors' choices. Some scholars have even suggested that while editors' access to restricted documents led their conflated editions of Shakespeare's King Lear to long remain unquestioned, "[p]hotography, by holding the mirror up to the copy-text, has ended their status as an elite"; now that Lear's textual kingdoms have returned to their proper divisions, "a more appropriate role for [editors] now is as commentators on the icon of the text rather than as atomizers of it, and as manipulators of its fragments" (MCLEOD 1983, 189). However, claims that the affordances of digital scholarly editions mean "students of a text will more readily than was ever the case in print editions be able to confront textual cruxes for themselves" are exaggerated (SHILLINGSBURG 1996, 166). ${ }^{10}$ In order to interrogate an editor's account of a copy text, a reader of a digital edition, like the reader of a print edition, is still required to be not only literate in the processes of textual transmission but also motivated to investigate textual transmission in the first place. Though ready access to the building blocks of eclectic editions can serve to demystify the process of scholarly editing with all of its emendations and

9. "Considering the Scholarly Edition in the Digital Age: A White Paper of the Modern Language Association's Committee on Scholarly Editions" (2015) can be accessed at https://scholarlyeditions.mla.hcommons.org/cse-white-paper/.

10. The online advertising copy for the third and latest edition of the Norton Shakespeare, which identifies as a "born-digital" text, likewise offers students "additional versions of many texts for comparison. Students are able to compare the Folio and Quarto texts of King Lear and scenes from other plays using an innovative side-by-side scrolling view option. Students can also compare the text to corresponding facsimile pages from the Hinman First Folio and from the quartos" (http://books.wwnorton.com/books/webad.aspx?id=4294987060). 
substitutions, what such a recourse to digital facsimiles actually and implicitly displays to most readers is the high degree of editorial interference that transforms an archival document into a modernized readers' edition. To put it another way, the accompaniment of facsimiles and transcriptions of an edition's copy text means that the reader of a digital scholarly edition can see at a glance that an editor's job does not end with the reproduction of primary documents to make them available to readers. Editorial labor also involves a series of interpretive and organizational actions designed to make texts more intellectually accessible. The authority of the editor to speak on behalf of the text is therefore not diminished by the affordances of the new technologies that enable documentary reproductions: it is intensified.

In the case of English Renaissance texts like the First Folio, readers of the ISE can use its F1 facsimiles to see that one of Bevington's first steps towards accessibility was the modernization and standardization of early modern spelling. Like all modern Shakespeare editions, Bevington's As You Like It removes extra e's, substitutes the modern $s$ for the perplexing and outdated grapheme of the long-s, and adopts current orthographic conventions for $u / v$ and $i / j$. He also re-punctuates the text. Though to most scholars these changes are minor, non-specialist readers can see them as significant and necessary modifications (it is the alienating effect of early modern spelling and orthography on a general reader that leads to the convention of modernization in the first place). The facsimile enables a reader to see the magnitude of the changes that occurred in an editor's translation of an old document into a new but more familiar linguistic form, and such an effect can easily overshadow a reader's potential for interrogating a crux like Charles's "hee" and "she". In the same way, A Social Edition of the Devonshire Manuscript's transcriptions render that document's difficult hands legible for its users using their modern graphic equivalents. While the texts of the poems aren't modernized, they are nonetheless made more accessible by the collective efforts of the team of expert paleographers whose work undergirds the edition, a fact that is unchanged by the editors' willingness to offer users access to facsimiles.

The appearance of facsimiles in a modernized scholarly edition of an English Renaissance work thus reinforces an editor's authority to act as a textual agent; however, it does so in very general terms. These transcriptions and modernizations of the texts of canonical authors are so common that it can be difficult to locate any individual editor's specific contributions within their remit. This is especially true in the case of Shakespeare, where 
modernized editions are the norm rather than the exception. ${ }^{11}$ While some series do incorporate new textual scholarship to produce new solutions to old cruxes and thereby establish fresh texts, many series simply reproduce existing texts and, in so doing, uncritically accept the textual scholarship that informed their original production. What this means is that often the only thing that is truly new about a "new" Shakespeare edition is its envelope of scholarly commentary designed to supply the difference between the world of Shakespeare's very-long-ago-then and our very-modern-now. It is this aspect of an editor's job that I am interested in investigating further.

In a scholarly edition, an editor's assumed authority to speak of the text in her role as a scholar with a proximity to limited documentary material (access to copies of the First Folio or to manuscripts in an archive) is often extended to provide her with authority to speak for the text as a commentator, to interpret its significance for less informed readers and mediate the way that they experience its meaning. As the MLA white paper authors note, a scholarly edition is "typically prepared with an audience of scholars and students in mind" and "may also have pedagogical aims related to how it presents information and supports learning" (Modern Language Association of America 2015). The editors of the Devonshire MS agree: "The work of the editor of the social edition is to make this kind of [interpretive] curation possible for members of the community of practice to undertake. By acting as a facilitator for community enrichment, the scholar or scholars heading up a social edition project must demonstrate considerable editorial skill in identifying possible avenues for interpretation and technological sensitivity in finding ways to make this kind of editing work" (Siemens et al. 2012, $460 \mathrm{n} \mathrm{22).} \mathrm{As} \mathrm{part} \mathrm{of} \mathrm{the} \mathrm{process} \mathrm{of} \mathrm{creating} \mathrm{a} \mathrm{scholarly} \mathrm{edition,}$ then, editors imagine the particular needs of their readers and supplement the newly edited text with a paratextual commentary designed to accommodate them.

On the surface, scholarly commentary seems to endorse a hierarchical model similar to the one for editorial access that I described above; however, instead of documentary access, the foundation of a commentator's authority to interpret a text has traditionally been found in her ability to draw on the highly specialized linguistic and historical knowledge that

11. The standard authority on modernizing Shakespeare's texts, which is often adopted to accommodate the modernization of the texts of other Renaissance dramatists, remains Stanley Wells's "Modernizing Shakespeare's Spelling” in Wells and TAYLOR 1979. 
allows her to explain the text for an audience who is believed to require such guidance. Consequently paratextual features like introductions and glosses have become critical battlegrounds: as they attempt to signal their improvement over competing editions, editors have offered increasingly larger and more copious notes in the margins, conspicuously indicating their ability to better contextualize and explicate. ${ }^{12}$ For Clayton J. Delery (1991, 63), this paratext enables editors to position themselves as "subjects presumed to know", scholarly elites who can decode the slips in both textual transmission and the vagaries of historical accident in order to present fragmented historical texts as knowable and unified wholes: instead of textual cruxes, antiquated references, and obscure language, an editor provides her text with standardized spelling, interpretable syntax, and a clarity of meaning. This ethos of "presumed knowing" holds regardless of an edition's medium: even though the affordances of hypermedia can enable the reader of a digital scholarly edition to jump around a text in a non-linear fashion, the affordances of the scholarly edition itself are designed to filter a reader's experience of a text through an editor's informing gaze. As Laurie Maguire notes, "[w]hen one buys one's first Shakespeare (whether individual volume or complete works), the editor's textual collation, glosses, and introduction, helpful and interesting though they may be, are ancillary to the text; in subsequent purchases, they are the reason for buying the text" (1999, 60, emphasis added). ${ }^{13}$

12. This reframing of old texts within new and improved paratextual contexts was also particularly important for Renaissance printers and publishers who needed to distinguish their offerings from those of their competitors. For example, two of Robert Wyer's three editions of the extremely popular little English herbal known as Banckes' Herball, in print from 1525, copied much of the text of its predecessors but (erroneously) reframed the herbal as the work of Aemilius Macer (STC 13175.8c; STC 13175.13c). William Powell followed a similar strategy in his publication of 1550, advertising his book as A lytel herball of the properties of herbes newely amended and corrected, with certayne addicions at the ende of the boke [as] appoynted in the almanacke, made in M.D.L. the xii. day of February by A. Askham (STC 13175.13).

13. The advertising copy for the third edition of The Norton Shakespeare again offers an example: "The Norton Shakespeare brings to readers a meticulously edited new text that reflects current textual-editing scholarship and introduces innovative pedagogic features. Created by an expert international team of textual editors, the digital edition offers early authoritative texts for each of Shakespeare's works in editions free from excessive emendation and intervention [. . . ]. Every play introduction and all notes, glosses, and bibliographies in this edition 
New Shakespeare editions come out with such regularity that it is necessary for scholars to highlight the differences between one edition and another, but an attempt to use new commentary to remedy the deficiencies of previous editions can be found even in the defenses of less frequently published texts. The editors of A Social Edition of the Devonshire Manuscript quote Arthur F. Marotti in explaining that while some of the manuscript's verses have appeared in scholarly editions of the collected works of Sir Thomas Wyatt, these editions "'distort [the] character' of the Devonshire Manuscript. [. . .] The Devonshire Manuscript is much more than an important witness in the Wyatt canon; it is also a snapshot of the scribal practices of male and female lyricists, scribes, and compilers in the Henrician court, as well as the first example of men and women writing together in sustained fashion in English". A Social Edition will therefore "move beyond the limitations of an author-centered focus on Wyatt's contribution in isolation, and concentrate on the social, literary, and historical contexts in which the volume is situated as a unified whole" (SiEmens et al. 2012, 135).

Printed editions have long used paratextual elements like appendices or marginal commentary to signal editorial intervention or critical dispute. But because all editorial praxes create meaning, readers benefit when editorial labor is made explicit to users, and new media offers opportunities for rendering old information - and old forms of scholarly authority — in new ways. Hans Walter Gabler asserts that digital scholarly editions should consist of "a relational interplay of discourses, dynamically correlated both among themselves and with an edition's readers and users: that is, to a paradigm once again of text and ongoing commentary" (2010, 43). What I've argued above is that though it may seem like the digital scholarly edition has enabled affordances that democratize the relationship between editors and readers, some of these affordances can actually reinforce traditional modes of editorial authority, even in editions that espouse egalitarian ideals. Though the editors of A Social Edition of the Devonshire Manuscript insist that Web 2.0 technologies are an important step in leveling the intellectual playing field between traditional scholars and a larger public, their work is supported by the very same forms of citation and scholarly credit that traditionally accompany printed scholarly editions. The project's editors may write that "ii]ncorporating social media and web 2.0 practices into scholarly editing recasts the primary editor as a facilitator rather than

have been reconsidered to incorporate reviewers' detailed suggestions, and new textual introductions and performance notes preceding each play reflect new scholarship in these fields". 
progenitor of scholarly editions", but their efforts are bolstered by a bibliography of more than five hundred items of peer-reviewed scholarship (SIEMENS et al. 2012, 153). Though the medium of delivery has changed, the traditional signaling of authority via demonstrated access to long lists of specialized scholarly material has not. Fortunately, the other discourses of digital scholarly editions that Gabler identifies as having specific user- and reader-directed functions are better able to make editorial and critical work legible to readers. When figured not as a traditional list of works cited but as a relational web of knowledge, a digital scholarly edition's use of citation, annotation, and commentary can transform editorial authority from a traditional top-down hierarchy into a lateral and contingent arrangement that makes room for readers' participation in the production of knowledge.

The chief means through which digital editions can enhance reader engagement with textual transmission is through the reframing of editorial work. Making editorial labor visible to users of a scholarly edition is valuable because few readers intuitively understand editors' mediating role. Without an explicit intervention that clarifies how the makers of documents shape and present texts, authors and their creative genius quickly become the organizing principle that structure readers' understanding of textual agency. This ideal of an author's genius is furthered by an "ethic of invisibility" that subsumes editorial and publication labor under the banner of an author's name. ${ }^{14}$ To counteract such impressions, instructors working with early modern texts often familiarize their students with print and manuscript media by visiting rare book collections, or, when these are unavailable, making use of printed facsimiles or electronic resources such as ProQuest's Early English Books Online (EEBO), the British Library's Shakespeare in Quarto, or the Folger Shakespeare Library's Digital Image Collection (LUNA) in order to illustrate the non-authorial agents attendant on the materialities of textual transmission. But there are costs to these methods: though they are helpful in demonstrating the collaborative nature of book-making in the early modern period, the chronological or collection-specific limitations placed upon such resources can mean they often stop short of exploring the translation of early modern books from their original incarnations to their modern classroom equivalents, thereby

14. I lift the term "ethic of invisibility" from Leah Vosko, as quoted in Cullen 2012, 7 . 
contextualizing textual transmission and editorial interference as a past event rather than as a continuing one. ${ }^{15}$

There is a solution: the lens of the social text is able to highlight the persistent nature of an editor's mediating role by conceiving of texts as the products of a collective conversation between the various agents involved in their production and reception. Editors can use the affordances of digital texts to reframe their assumption of authority in two ways: firstly, by explicitly exposing the amount and nature of the editorial labor that lies behind their editions, and secondly, by recognizing readers' crucial place within the meaning-making process. In other words, rather than simply assuming the mantle of "subjects presumed to know" because of their access to restricted documentary texts, digital editors can highlight the ways that scholars use others' research to construct the credibility necessary to speak authoritatively about a text and its authors. ${ }^{16}$ My earlier model of editorial authority based on documentary access suggested a causative relationship between editors, authors, texts, and readers in which editors begin and influence the meaning-making process. Such a top-down teleology inadvertently implies that readers don't influence editorial behavior, though readers' anticipated needs are what determines an editor's choices for scholarly commentary and other forms of paratext. A more recursive model, in contrast, accepts that editors' authority to speak on behalf of their edited texts in their commentary derives from readers being able to recognize that authority. ${ }^{17}$ The question for editors of digital scholarly editions rests in

15. While some archival resources, such as the ISE, Shakespeare in Quarto, and LUNA are open access, many electronic archives are locked behind pay walls that limit their adoption and therefore their utility. As recent news coverage of '\#ProQuestGate' suggests, subscription to electronic archival databases such as EEBO is largely limited to those students and faculty affiliated with large research universities, adding an additional restriction of access to archival material for the majority of students and scholars (see Straumsheim 2015).

16. Theories of reader-response have long insisted upon the primacy of the experience of reading; as D. F. McKenzie argues, "readers inevitably make their own meanings. In other words, each reading is peculiar to its occasion, each can be partially recovered from the physical forms of the text, and the differences in readings constitute an informative history" $(1999,19)$.

17. My thinking about the ways that truth is constructed via testimony and cultural practice is indebted to SHAPIN I 994. 
how they can use their new medium to better show editors' traditional position within a wider ecology of scholarship..$^{18}$

\section{II}

Recent studies in cognitive psychology can help editors better understand the ways that readers of digital texts construct and evaluate systems of knowledge. The redistribution of textual agency and interpretation I have highlighted above is bolstered by studies of "Transactive Memory Systems" (TMS), models that conceptualize group cognition as knowledge sharing and retrieval processes that empower individual users to access subjectspecific information from knowledgeable experts. ${ }^{19}$ While businesses are beginning to use theories of TMS to inform their building of management software or policies to better enable, for example, international and transcontinental collaboration between employees, the psychology is rooted in long-established structures of human interaction. Transactive Memory Systems are behind, for instance, relationship dynamics in which one partner is responsible for issues pertaining to the car and garden, while the other partner handles matters relating to the dog's health or the dates of future family celebrations. The success of TMSs depends upon acknowledging the affinity between multiple individuals who are each responsible for maintaining separate branches of knowledge; the systems work not because one person knows everything, but because knowledge is recognized as provisional, distributable, and mutually beneficial. Through transactive memory, individuals externalize a significant percentage of their knowledge, arrang-

18. The MLA white paper offers a related perspective in its authors' assertion that a scholarly edition is "motivated to support further scholarship" and is "understood to be part of larger scholarly enterprise, ultimately taking its place alongside and possibly in combination with similar works and allowing forms of analysis and engagement beyond those of its editorial intention, supporting further (re) mediation, (re)construction, and (re)mix in the advancement of scholarship in acts that allow, for example, the construction of other editions that may explore alternative hypotheses or challenge notions of authorial intention and editorial authority". The modalities of digital editions are particularly enabled for easy networking and linking of data, facilitating "environments within which the user can occupy the role of a contingent editor, examining less-traveled editorial paths and their interpretive consequences".

19. The notion of transactive memory was first explored in WeGNER 1987. Much of the following information about transactive memory is indebted to JACKsON 2011. 
ing recall of the location of stored information rather than the information itself. In such a model, the "where" or "whom" is prioritized in memory, allowing much of the "what" to be forgotten.

The science of Transactive Memory Systems offers implications for the design of digital editions to better enable users to recognize the contingencies and dependencies of scholarly labor. The means by which individuals recognize others as potential knowledge resources is the TMS "directory", which describes a shared mental model of labels that outline the responsibilities for individuals within a given system. The directory stores information about the various roles played by experts in the group as well as offers a dataset that reflects the accuracy of information, allowing users not only to locate expertise within a given information system, but also to review evaluations that explain why such experts may be trusted. ${ }^{20}$ According to cognitive theorists, such TMS evaluations work most efficiently when the assessments of expertise are objective rather than self-declared (BRANDON and Hollingshead 2004, 639). It is clear that authority over a knowledge domain is something that has to be recognizable by users rather than something that is simply assumed by a would-be expert.

The implications of the TMS directory model for editors of scholarly editions are clear: users benefit when editors take pains to demonstrate the ways that their expertise functions within a broader credentializing system. The difficulty, however, arises in the fact that scholars typically operate with a different directory model than do the users of their editions. An editor often writes her commentary notes on the basis of information that she receives from another scholar, whose work in turns relies on others. Systems of print citation have traditionally served to acknowledge these scholarly affinities and dependencies, and printed affordances like bibliographies list all of these dependencies in a single place. A listing of publisher information helps to identify experts who have been credentialized through peer review and enables scholars to make judgments about those who have not. But while editors may be sufficiently conversant in early modern scholarship or strategies of peer review to know whom to consult as a trusted expert on, say, issues like the modernization of Shakespeare's language or the censorship of Elizabethan playbooks, non-specialist readers may not even be aware that such specialized knowledge exists in the first place, which prevents them from seeking it out. The system does not work

20. Historian Steven Shapin likewise locates early modern understanding of scientific "truth" to group dynamics. In his words, "practical epistemology was embedded within practical social theory" (1994, xxvii). 
as efficiently as it could. ${ }^{21}$ Editors might therefore consider the ways that they can use the affordances of their digital editions to make readers better aware of the networks of scholarly and intellectual labor that underwrite their projects. These structures may take various forms, including more thorough and more self-conscious commentary notes, annotated bibliographical listing of resources, and greater and more explicit consultation with librarians and other experts in information literacy.

Other implications of TMSs are more challenging of established editorial practice and suggest that digital editions would also benefit from considering ways of integrating the experiences of newcomers or end users into their directory systems in ways that demonstrate that readers' activities are not only desired, but also relevant to a project's outcomes. Though digital projects often envision popular reader engagement taking the form of "comment threads" appended to the ends of articles or pages, this is not the only way that users can participate in the meaning-making process. (In their Iter edition, A Social Edition offers the opportunity for users to leave comments on individual paragraphs.) For example, in much the same way that Google changes the ranked order of web pages as a result of folksonomic linking, algorithmic web design enables alternatives that can change the order or appearance of editorial paratexts in response to readers' activities. Further, editors of digital editions may want to conspicuously demonstrate to their users that their projects are attentive to the ways in which their texts are used and reused..$^{22}$ Such attention might include updates that demonstrate how an edition's data elements have been sampled or reused by other projects for distinct purposes and goals, as the MLA white paper suggests. These changes may be viewed as challenges because enabling readers and fellow users to take part in a shared knowledge model requires editors to give over some of their powerful subjectivity, particularly to those users who are not themselves scholars. Editors can find themselves resistant to the notion that there are other potential agents beyond those

21. "Until members understand which members possess what expertise, they will be less efficient at retrieving information and communicating about task elements that had been previously organized as shared higher-order information. Members must again develop shared higher-order concepts before they can efficiently retrieve and coordinate what members know" (LEw is et al. 2005, 587).

22. Eric Johnson, creator of the Open Source Shakespeare, added a Text Search Statistics page to the site in September 2012 to enable users to parse not only the most-searched keywords, but also the rate and frequency of searches in the past hour, day, week, month, and year. 
of the scholarly and credentialed who have an interest in the establishment of a text and its author(s). ${ }^{23}$

Scholarly editors can also benefit from this research into Transactive Memory Systems by considering the ways that such distributed knowledge and retrieval processes might shift technical presentations of editorial and critical activity. Instead of being cloaked in an "ethic of invisibility" by assuming that editorial labor and traditional citation practices are selfexplanatory, editors can make use of digital affordances to provide not only textual and scholarly commentary, but also to direct readers' attention to the ways an editor was able to provide such information in the first place. In some cases, an affordance as simple as a hyperlink can enable readers to see the source of a commentary editor's claims. For example, instead of merely stating that the phrase "make ballads of you" (TLN 94) is a warning to avoid infamy, Joost Daalder's edition of Thomas Dekker and Thomas Middleton's The Honest Whore, Part 1 for the Digital Renaissance Editions directs its readers outwards to investigate how ballads serve as "scurrilous compositions by young vagabonds" for themselves:

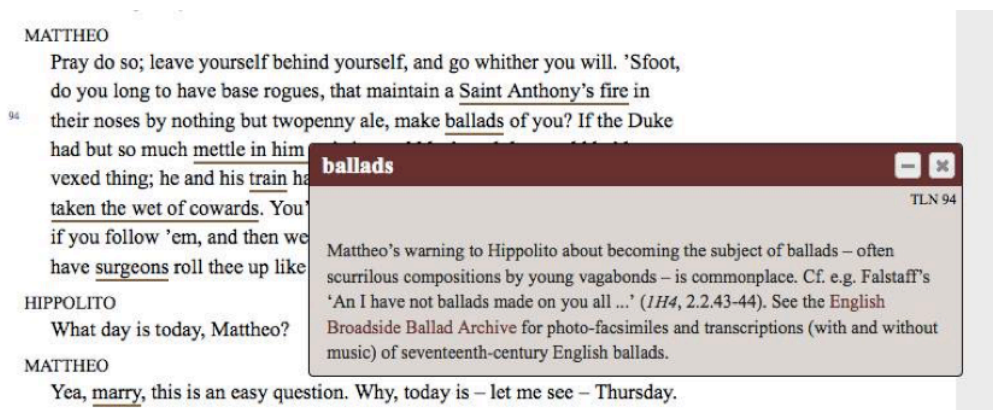

Figure 3. Joost Daalder's edition of The Honest Whore, Part 1, for the Digital Renaissance Editions. Screenshot by the author.

TMS processes bolster the acknowledgement of the contingencies of scholarly and editorial work because a necessary condition for the development of transactive memory is cognitive interdependence: individuals

23. Studies of Shakespeare's role in popular culture have long affirmed, in Marjorie Garber's terms, that "Shakespeare makes modern culture and modern culture makes Shakespeare" (2008, xiii). For a comprehensive look at this phenomenon, see LANIER 2002. 
within the network recognize that their outcomes are dependent on the knowledge and expertise of others, while simultaneously recognizing that others' outcomes are similarly dependent on their own knowledge and expertise. But while scholarly editors working within traditional systems of acknowledgement and accreditation may themselves understand the implications of their use of standard peer-reviewed sources of information such as the English Short Title Catalogue, Oxford Dictionary of National Biography, or the Oxford English Dictionary, students and general readers are by definition less conversant in such norms. They benefit from the provision of additional context that can be provided by resources as straightforward as an annotated bibliography that clarifies the status of these kinds of watershed tools.

Research shows that Transactive Memory Systems require three characteristics to function effectively: specialization, coordination, and credibility. Specialization is the most basic feature of a TMS, as it is through specialization that knowledge differentiation is enabled: "if there is no knowledge differentiation between group members, there is no need for a directory containing knowledge location and access information: one can ask anyone anything" (JACKsON 2011, 418). As I've noted above, experts usually work with a directory that is distinct from the directory used by non-experts, and so reconciling the needs of both scholarly editors and the readers of an edition requires deliberate and thoughtful effort as each group identifies specialization differently. Fortunately, this complication has advantages. Because knowledge of textual scholarship is somewhat limited even amongst scholars who regularly use edited texts, editors who provide additional information about editorial processes as part of their editions' pedagogical aims will establish the bona fides not only of a particular editor or editors, but also of textual editing more generally. In addition, because digital scholarly editions often require collaboration among numerous agents who are responsible for distinct elements of an edition, the specialization requirements of Transactive Memory Systems suggest that the functions of individual roles need to be fully described in order to be effective. Publishing strategies that rely merely on acknowledgement and credit without such explanations will be much less useful to non-specialist users.

The second TMS characteristic of coordination refers to the effective use of the knowledge directory in order to retrieve information with speed and accuracy. This TMS requirement clearly depends on effective specialization, as users must first understand the roles possible within the knowledge system of the digital edition before they can seek out their various 
services. (Readers need to be told, for example, how the responsibilities of a general textual editor of a project like the Internet Shakespeare Editions or Digital Renaissance Editions differ from the responsibilities of a play's individual editor.) Coordination in digital scholarly editions can best be served by interface design that clearly delineates not only the affordances of digital media, but also of the valuable resources appended to the complex texts of all scholarly editions, regardless of their medium. Design interfaces should ideally reinforce the value of all seven strands of Gabler's (2010, 46) editorial discourses: text, emendation apparatus, historical collation, textual notes, textual introduction, annotation, and commentary. Rather than diminish or hide some of these elements such as collation notes or lists of works cited (which are all-too-frequently relegated to an appendix), digital scholarly editions can use thoughtful design to reinforce the myriad activities of editors and editorial teams, as in the upcoming redesign of Daalder's edition of Honest Whore, Part 1, which will distinguish between his contributions and those of collaborator (and DRE coordinating editor) Brett Greatley-Hirsch.

The third and final necessary characteristic for effective Transactive Memory Systems is credibility. Credibility 'reflects the group's members' perceptions about the reliability of other members' knowledge, but also of other sources of information such as reports or databases" (JACKSON 2011, 419). In a TMS, credibility is vital not only because it determines the quality of the information output, but because the credibility of an expert influences whether or not TMS group members attempt to retrieve information from that expert in the first place. ${ }^{24}$ As self-declaimed proficiency is found to have little correlation with users' willingness to accept such expertise, cognitive theorists surmise that "expertise should, as much as possible, be decoupled from self-assessment", as otherwise "without an objective benchmark, people may fetch advice from an inferior source and have misplaced

24. Cognitive psychologists have also begun to research the way that cultural stereotypes associated with race and gender extend into assumptions about domain specialization; for example, women are frequently associated with expertise in affairs pertaining to children or domestic affairs irrespective of their actual affinities, while men are often similarly associated with technology and mechanics. Because the assumption of such roles gradually enables individuals to become experts in their respective fields, these stereotypes become self-fulfilling prophesies that re-inscribe hegemonic social norms. Similar inadvertent endorsements of hegemony can play out in editing as well; for an exploration of this issue, see MAguire 1999 and TAylor 1989. 
confidence in its value" (JACKson 2011, 419, 420). The TMS model suggests that a project's assumption of de facto editorial authority may be insufficient or even counter-effective - because the performance of editorial authority needs to be visible to be understood, editors will benefit from shedding the cloak of invisibility so that readers can better evaluate editors' crucial role in knowledge-making.

Interdependency and intertextuality have always been a part of scholarly labor, signaled in both print and manuscript in the form of citation of previously published works. What is different in the case of digital scholarly editions is that in this medium, modern readers' sense of the credibility of a cited source is bolstered when they are readily able to encounter the resource upon which expertise the current text depends. Though the physical limitations of books constrain their ability to "network" or otherwise use their forms to highlight their dependencies on other works of scholarship, digital editions are subject to no such restrictions. Daalder's scholarly authority in his note on ballads is therefore reinforced by the appearance of a hyperlink regardless of whether a reader chooses to investigate it further. The affordance explicitly radiates outward to imply that digital projects are part of a larger ecology of knowledge relative to their analog forebears. Scholars may understand that forms of traditional citation function in much the same way to direct readers to supporting works of scholarship, but users of digital media are primed to value resources that exist online over those that do not.

These studies in cognition and editorial interventions could not come at a better time. Even though commentary notes and other paratextual materials previously signaled editors as authoritative subjects with access to limited documentary materials and to experts in specialized information, modern readers' ever-present smartphones allow them their own, nearly constant access to folksonomic Web 2.0 platforms like Wikipedia and algorithmic search engines such as Google. As Joshua Cohen muses in my second epigraph, those of us who are not Harold Bloom tend to rely on our phones as extensions of our memories. Likewise, our present circumstances in the information age have diminished much of editors' traditional elite status as "subjects presumed to know". The convenience of Internet resources and online search engines offers readers the expectation of an external and artificial Transactive Memory System that can be accessed at any time or in any place. While much of the publicly accessible material available on the web lacks the peer review and other forms of legitimation that back up scholarly claims to authority, the web's ubiquity with modern readers eager to learn more about a particular subject should give modern 
commentary editors pause. ${ }^{25}$ Though Wikipedia-founder Jimmy Wales's claim that "if it's not on Google, it doesn't exist" is demonstrably untrue, such a view accurately articulates the beliefs of many modern readers of hyperlinked media, who expect immediate access to cited material as a signal of its legitimacy. ${ }^{26}$ This immediate access stands in the former place of a commentary editor's traditional authority to declare certain pieces of information legitimate - for many readers today, if they can get access to such data by hyperlink, it must therefore be accurate. For those engaged in the slow work of editing, the ubiquity of Google and its effects on transactive memory makes losing the cloak of invisibility even more crucial. In an age when the term book has moved beyond a description of a bound, inkbased codex to include e-readers, born-digital materials, and user-produced content, editors can no longer rest secure that their readers will simply accept claims to authoritative knowledge, nor will online readers necessarily understand the assumptions of legitimacy packed into a long works cited page of printed sources. Because on the web hyperlinks serve as their own form of legitimization, alternative and traditional forms of scholarly citation now need to be explicitly constructed and contextualized in ways that are highlighted for users, not hidden from view.

The aforementioned requirements of effective Transactive Memory Systems (cognitive interdependence, credibility, specialization, and coordination) - particularly the former two - can serve to fill the gap between editorial labor and modern readers' expectations. Studies of Google's effects on memory seeking to locate the "cognitive consequences of having information at our fingertips" have noted "when we are faced with a gap in our knowledge, we are primed to turn to the computer to rectify the situation" (Sparrow et al. 2011, 776). When people believe that they will not need information later, they tend to forget it; in other words, people do not make an effort to retain information if they believe that they can readily access it again: "Because search engines are continually available to us, we may often be in a state of not feeling we need to encode the information internally. When we need it, we will look it up" (Sparrow et al. 2011, 777).

25. The MLA's Committee on Information Technology has long asserted the validity and credibility of electronically published scholarship; however, even scholarly digital projects provide challenges to traditional systems of peer review and assessment; for an overview, see HiRsch 2011.

26. The quotation was ascribed to Wales in a 2006 article in the New Yorker by Stacy Schiff, where it was clearly taken out of context; however, the phrase has since become aphoristic. 
Though human memory systems are unquestioningly adapting to new technologies, it is perhaps more accurate to say that new technologies are being built in response to the norms of human memory systems. The distinction, however, is in the fact that whereas information-sharing processes were once exclusively social and clearly subjective, the advent of Web 2.0 and wireless technologies has served to extend our dependency on the superficially objective Internet. As we become, in one cognitive theorist's terms, "symbiotic with our computer tools, growing into interconnected systems that remember less by knowing information than by knowing where the information can be found", we increase the degree to which we need to learn to evaluate critically the locations from which knowledge may be retrieved (Spar row et al. 2011, 778). Such conclusions have repercussions for scholarly editors: in order to construct the credibility needed for the establishment of effective cognition-based trust, editors need to explain the terms of the simplifications, clarifications, and elisions of ambiguities that they use to construct their editions, thereby going beyond the traditional forms of bibliography and citation found in earlier media. While these additional responsibilities are beyond the affordances of scholarly editions in print, digital editions are well positioned to accommodate these new demands on editors. Such role-identification behavior serves to disclose the division of responsibilities that leads to the creation of an edited text and is "positively related to the emergence of shared team mental models and transactive memory" (JACKSON 2011, 411).

Essays such as this one often conclude with a series of recommendations designed to suggest that the issue at hand can be attended to by observing a select group of protocols; however, because the research into transactive memory is still new, and because studies of the long-term social effects of the omnipresence of the web in our daily lives are still underway, it is perhaps too soon for editorial theorists to issue guidelines as to the way digital scholarly editors should proceed. So, in lieu of a set of recommendations, I offer a short series of interrelated questions for scholarly editors engaged in digital projects:

1. Does the culture of your project engage in an "ethic of invisibility" by hiding editorial interventions? Is this invisibility truly necessary? What would happen if you did away with all or some of it?

2. Does your project make the contingencies of editorial and scholarly decision-making visible and interpretable to non-specialists? If it doesn't, why not? 
3. Does your project assume that its users already understand the history of the scholarly networks that have traditionally powered editorial labor? Does it explain the mechanisms of textual editing or literary and historical scholarship as a series of choices dependent on the work of predecessors?

In the preceding pages I've suggested that modern readers' new relationship to information problematizes an editor's traditional authoritative position while simultaneously offering a valuable opportunity for reframing discussions about the reliability and accessibility of scholarly evidence. The insights of cognitive theorists on transactive memory systems have repercussions for all editors, but especially for those constructing digital scholarly editions of texts — the old model, Delery's editor as a "subject presumed to know", does not serve the particular needs of readers using an online edition as a part of their extended TMS network. When looking for information from experts within a TMS, readers of digital editions require the cognitive interdependence that enables them to view their research activities as part of a larger ecology; while they may not have as much expertise as the editor-scholars whose work they seek out, these readers nonetheless evaluate the information they have been provided. But they need tools in order to do so.

The presentation of citation information within a scholarly edition offers a valuable opportunity for editors to demonstrate to users that their authority is not absolute but contingent, reliant on a larger and integrated scholarly ecology that extends backwards through decades, and sometimes through centuries, of scholarship. But even the most innovative and selfaware scholarly editions such as A Social Edition of the Devonshire Manuscript miss the opportunity to reframe editorial and scholarly authority, falling back on traditional systems of print citation such as works cited lists and bibliographies, even as they attempt to "shift [ . . . power from a single editor to a community of active readers and mediators" (SIEMENS et al. 2012, 153). While A Social Edition of the Devonshire Manuscript admirably demonstrates the provenance and social circumstances of the original documents that serve as copy for the edition, it nonetheless falls short of its stated goal of modeling "a new kind of scholarly discourse network that hopes to eschew traditional, institutionally reinforced, hierarchical structures and relies, instead, upon those that are community-generated" (Siemens et al. 2012, 154). It is true that Web 2.0 is defined by its ability to allow users to generate content that can be shared with other users. But 
as physical documents, material texts have always allowed this - as handwritten marginal notes to printed works, palimpsests, or even the socially networked nature of the multiple hands in the Devonshire MS itself widely attest. Without a deliberate re-conception of the ways that intellectual authority is manifested in the longstanding citation practices associated with both manuscript and print culture, the tools of Web 2.0 will merely re-inscribe existing social and scholarly hierarchies. My proposal requires that we take the theories of social editing one step further to foreground the networked contingencies of the endeavor of scholarship - and scholarly editing - itself.

By characterizing their work through the four specific dimensions of Transactive Memory Systems (cognitive interdependence, specialization, credibility, and coordination), commentaries in scholarly editions can call attention to scholarly networks of peer-reviewed knowledge that are usually not accessible through Google searches, broadening the pedagogical function of scholarly editions to dovetail with recent studies in information literacy. As a result of the World Wide Web, algorithmic searching, and omnipresent smart phones, we are now in a position where more of us indeed, potentially all of us - are subjects presumed to know.

The Ohio State University

\section{Works Cited}

Bevington, David, ed. 2013. William Shakespeare, As You Like It (Modern). Victoria, Canada: Internet Shakespeare Editions. Web. Accessed 21 June 2015.

Brandon, David P. and Andrea B. Hollingshead. 2004. "Transactive Memory Systems in Organizations: Matching Tasks, Expertise, and People”. Organization Science 15:6: 633-44.

Brown, John Russell. 1960. "The Rationale of Old-Spelling Editions of the Plays of Shakespeare and his Contemporaries". Studies in Bibliography 13: 49-67.

Cohen, Joshua. 2018. "Stories as Prayer: A Conversation Between Joshua Cohen and Harold Bloom". Los Angeles Review of Books. 16 August 2018. Web. https://lareviewofbooks.org/article/stories-as-prayer-a-conversation-between-joshua-cohenand-harold-bloom/ . Accessed 20 August 2018.

Crompton, Constance, Daniel Powell, Alyssa Arbuckle, Ray Siemens, with Maggie SHIRLEY and the Devonshire Manuscript Editorial Group. 2014. "Building A Social Edition of the Devonshire Manuscript". Renaissance and Reformation / Renaissance et Réforme 37.4: 131-56.

Cowan, Yuri. 2012. "Reading Material Bibliography and Digital Editions". In Editors, Scholars, and the Social Text, edited by Darcy Cullen, 223-38. Toronto: University of Toronto Press. 
Cullen, Darcy. 2012. "The Social Dynamics of Scholarly Editing”. In Editors, Scholars, and the Social Text, edited by Darcy Cullen, 3-32. Toronto: University of Toronto Press.

DaAlder, Joost, ed. 2015. Thomas Dekker and Thomas Middleton, The Honest Whore, Part 1 (Modern). Internet Shakespeare Editions, University of Victoria: Digital Renaissance Editions. Web. Accessed 5 November 2015.

Delery, Clayton J. 1991. "The Subject Presumed to Know: Implied Authority and Editorial Apparatus". Text 5: 63-80.

Gabler, Hans Walter. 2010. "Theorizing the Digital Scholarly Edition”. Literature Compass 7.2: 43-56.

GArber, Marjorie. 2008. Shakespeare and Modern Culture. New York: Random House.

Hirsch, Brett. 2011. "The Kingdom has been Digitized: Electronic Editions of Renaissance Drama and the Long Shadows of Shakespeare and Print". Literature Compass 8/9: 568-91.

JACKson, Paul. 2011. "Requirements for an information system to support transactive memory". VINE: The Journal of Information and Knowledge Management Systems 41: 401-27.

Johnson, Eric, ed. 2015. Open Source Shakespeare. George Mason University. Web. Accessed 5 November 2015.

LANier, Douglas. 2002. Shakespeare and Modern Popular Culture. Oxford, UK: Oxford University Press.

Lewis, Kyle, Donald Lange and Lynette Gillis. 2005. "Transactive Memory Systems, Learning, and Learning Transfer". Organization Science 16:6: 581-98.

Lyth, Peter J. 1993. "The history of commercial air transport: A Progress report, 195393". The Journal of Transport History: 166-203.

Maguire, Laurie E. 1999. "Feminist Editing and the Body of the Text". In A Companion to Feminist Shakespeare Studies, edited by Dympna Callagh an, 59-79. Oxford, UK: Blackwell.

McKenzie, D.F. [1986] 1999. Bibliography and the Sociology of Texts. Cambridge: Cambridge University Press.

McLeod, Randall. 1983. "Gon. No more, the text is foolish". In The Division of the Kingdoms Shakespeare's Two Versions of King Lear, edited by Gary TAYLor and Michael Warren, 153-93. Oxford, UK: Oxford University Press.

Modern Language Association of America. 2015. "Considering the Scholarly Edition in the Digital Age: A White Paper of the Modern Language Association's Committee on Scholarly Editions". Web. 2 September 2015. https://scholarlyeditions.mla. hcommons.org/cse-white-paper/ . Accessed 20 August 2018.

Neville, Sarah. 2014. "Nihil biblicum a me alienum puto: W.W. Greg, Bibliography, and the Sociology of Texts". Variants: The Journal of the European Society for Textual Scholarship 11: 91-112.

Palmer, Carol L. 2004. "Thematic Research Collections". In A Companion to Digital Humanities, edited by Susan Schreibman, Ray Siemens, and John Unsworth, 348-65. Oxford, UK: Blackwell. 
Schiff, Stacy. 2006. "Know It All”. The New Yorker, 31 July 2006. https://www.newyorker.com/magazine/2006/07/31/know-it-all. Accessed 20 August 2018.

Shapin, Steven. 1994. A Social History of Truth: Civility and Science in SeventeenthCentury England. Chicago: Chicago University Press.

Shillingsburg, Peter. 1996. Scholarly Editing in the Computer Age. 3rd ed. Ann Arbor: University of Michigan Press.

Siemens, Ray, Meagan Timney, Cara Leitch, Corina Koolen, Alex Garnett, with the ETCL, INKE, and PKP Research Groups. 2012. "Toward modeling the social edition: An approach to understanding the electronic scholarly edition in the context of new and emerging social media”. Literary and Linguistic Computing 27: 445-60.

Smith, Martha Nell. 2002. "Computing: What's American Literary Study Got to Do with IT?" American Literature 74: 833-57.

Sparrow, Betsy et al. 2011. "Google Effects on Memory: Cognitive Consequences of Having Information at Our Fingertips". Science 333: 776-8.

Straumsheim, Carl. 2015. "Preventing Another \#ProQuestGate". Inside Higher Ed. Inside Higher Ed. Web. Accessed 6 November 2015.

TAnselle, G. Thomas. 1989. "Reproductions and Scholarship". Studies in Bibliography 42: $25-54$.

TAylor, Gary. 1993. "The Renaissance and the End of Editing". In Palimpsest: Textual Theory and the Humanities, edited by George Bornstein and Ralph G. WiLLiAms, 121-50. Ann Arbor: University of Michigan Press.

1989. "Textual and Sexual Criticism: A Crux in The Comedy of Errors". Renaissance Drama 19: 195-225.

Taylor, Gary, and John Lavagnino, eds. 2007. Thomas Middleton: The Collected Works. Oxford: Oxford University Press.

Taylor, Gary, John Jowetr, Terri Bourus, and Gabriel Egan, eds. 20i6-i 7. The New Oxford Shakespeare: The Complete Works. Oxford: Oxford University Press.

Wegner, D.M. 1987. "Transactive memory: a contemporary analysis of the group mind". In Theories of Group Behaviour, edited by B[rian] Mullen and G[eorge] R. Goentahls, 185-208. New York: Springer Verlag.

Wells, Stanley, and Gary Taylor. 1979. Modernizing Shakespeare's Spelling. With Three Studies in the Text of Henry V. Oxford: Clarendon Press.

W. W. Norton \& Company, Inc. "The Norton Shakespeare". books.wwnorton.com. n.d. N.p. Web. Accessed 6 November 2015. 